\section{A "maternidade moderna" e a medicalização do parto nas páginas do Boletim da Legião Brasileira de Assistência, 1945-1964}

\author{
"Modern motherhood" \\ and the medicalization of \\ childbirth in the pages of the \\ Boletim da Legião Brasileira \\ de Assistência, 1945-1964
}

SILVA, Bruno Sanches Mariante da. A "maternidade moderna" e a medicalização do parto nas páginas do Boletim da Legião Brasileira de Assistência, 1945-1964. História, Ciências, Saúde - Manguinhos, Rio de Janeiro, v.25, n.4, out.-dez. 2018, p.1019-1037.

Resumo

Entre 1945-1964 o Brasil vivia uma acelerada modernização. Transformandose numa sociedade urbana, sob o jugo do higienismo, procurava refutar práticas e costumes considerados tradicionais e arcaicos. Nesse contexto, a figura tradicional da parteira é preterida socialmente para dar espaço ao conhecimento médico, que passa a incidir sobre o partejar e o maternar. Este texto analisa o Boletim da LBA, investigando o processo de medicalização e cientifização da maternidade e do parto, tomando em observação os embates científicos e morais sobre maternidade e parto que ocupavam as páginas da publicação oficial da maior instituição de assistência no país.

Palavras-chave: maternidade; modernidade; Legião Brasileira de Assistência; parto sem dor; parto hospitalar.

\section{Abstract}

Between 1945 and 1964, Brazil underwent an accelerated process of modernization. Increasingly urbanized and guided by the precepts of social hygiene, the country was keen to refute any practices or customs regarded as traditional or oldfashioned. As such, the traditional figure of the midwife was supplanted by medical knowledge, which came to exert influence on childbirth and motherhood. This text analyzes Boletim da LBA, investigating the medicalization and scientification of childbirth and motherhood and focusing on the scientific and moral clashes about motherhood and childbirth contained in this, the official publication of the country's largest welfare institution.

Keywords: motherhood; modernity; Legião Brasileira de Assistência; painless childbirth; hospital birth. 
Vivemos em uma nova Era na História da Civilização, deixando para trás um Mundo triste e arruinado (Boletim da LBA, 1 mar. 1946, p.7).

Nas primeiras décadas do século XX, especialmente após a Segunda Guerra Mundial, o Brasil experimentava grandes transformações, vendo sua população aumentar e se deslocar, majoritariamente, do campo para as cidades. Progresso e modernidade tornaramse expressões constantes nos imaginários e falas. O bombardeamento de propagandas e o incentivo ao consumo produziam novas representações e ideais de vida: a televisão, o automóvel, o cinema, os novos remédios etc. Essa conjuntura remete a um longo processo que transcorre desde o século XIX, período assinalado por um vigoroso esforço de submissão das sociedades a uma racionalidade modernizante.

Os preceitos de modernidade pareciam atingir todos os aspectos da vida, desde as ciências, a educação, forças armadas até modos de vestir e comportar-se. A modernidade açambarcaria, à sua maneira, os mais variados elementos da vida em sociedade, inclusive algo bastante tradicional e elementar - e natural - como a maternidade. ${ }^{1}$ Consolidam-se as representações de "mãe moderna" e "maternidade moderna", contribuindo para novas proposições também sobre o parto. No entanto, a aceitação e a concreta difusão de tais preceitos não aconteceram de modo uniforme e instantâneo, uma vez que podemos observar esforços que atravessam décadas para que esse imaginário e práticas se consolidassem efetivamente. Dessa maneira, no sentido de um claro esforço de submissão da maternidade à modernidade, esperamos no presente texto apresentar uma reflexão sobre o processo de exaltação do parto hospitalar, constituindo-se como norma moderna a ser seguida, uma vez que seria amparado e vigiado por médicos. Para tal, analisamos as ações da Legião Brasileira de Assistência (LBA) no período entre 1945 e 1964, por meio de sua publicação oficial, Boletim da LBA.

Fundada pela primeira-dama Darcy Vargas, em 1942, logo após a declaração de guerra do Brasil e sua entrada definitiva no combate mundial, a LBA trazia como missão prestar suporte às famílias dos combatentes da Força Expedicionária Brasileira (FEB), sobretudo em razão de os expedicionários brasileiros terem sido, em sua larga maioria, selecionados a partir de homens oriundos das camadas mais pobres da sociedade. ${ }^{2}$ Presidida, em geral, ${ }^{3}$ pela primeira-dama do país, a LBA era financiada pela Confederação Nacional das Indústrias e a Federação das Associações Comerciais do Brasil, contando também com aporte de verbas federais. É preciso assinalar que a LBA atuou por mais de cinquenta anos (1942-1995), e possuía seções estaduais em todas as unidades federativas, bem como em grande número de municípios. Isso é, além de longeva, a LBA também era ramificada pelo território brasileiro, potencializando seu poder de atuação.

O Boletim da LBA foi publicado pela primeira vez em janeiro de 1945, assumindo o propósito de facilitar a comunicação entre os soldados brasileiros em combate na Europa e suas famílias no Brasil, também servindo para divulgar as campanhas organizadas pela LBA. ${ }^{4} \mathrm{O}$ Boletim era uma publicação distribuída gratuitamente e que, apesar de sua produção dar-se na sede central da instituição no Rio de Janeiro, era enviado para as comissões 
estaduais em todo o território nacional, segundo atestam correspondências publicadas nas páginas do informativo. Sua ampla distribuição nos possibilita refletir sobre a importância dessa publicação em uma instituição tão ramificada no território nacional. Michele Barbosa (2017, p.171) afirmou que "muito do que foi realizado pela LBA pode ser analisado por intermédio dessas publicações e, apesar de iniciar em 1945, é possível conhecer a atuação da instituição desde sua criação, uma vez que algumas das ações iniciais também foram publicadas nos boletins". A autora construiu rica contribuição para a reflexão sobre a história institucional da LBA, ressaltando o protagonismo feminino no modelo de atuação criado em 1942; no entanto, Barbosa (2017) concentra-se no período do conflito mundial, isto é, até 1945, analisando apenas um ano do Boletim.

Iniciado em 1945, o Boletim atravessará a história da LBA, consolidando-se como sua publicação oficial e servindo de grande canal de comunicação de suas ações e projetos. Também se empenhará em transmitir e consolidar uma imagem positiva e atuante da LBA. O teor dos artigos publicados oscila entre o rigor médico, com longos textos sobre doenças e sua profilaxia, passando por artigos sobre puericultura para mães e até notas e textos bastante informais, como se "falasse diretamente às mães brasileiras". Quanto à periodização, o Boletim foi publicado bimestralmente, trimestralmente, semestralmente, e há vários intervalos em que não foi publicado, em geral em razão de agitação político-social, como o suicídio de Vargas, em 1954, ou a renúncia de Jânio Quadros, em 1961. Assim, dispomos de 77 edições. ${ }^{5}$ Sobre o Boletim, é preciso fazer duas observações: a primeira é que a vasta maioria dos textos não tem autoria identificada, assumindo assim uma postura de "fala oficial". A segunda é que, em um país com alto índice de analfabetismo, é possível constatar que a mulher/mãe pobre, público-alvo da LBA, não lia o Boletim, recebendo a atenção da LBA unicamente por meio de suas ações e campanhas. O Boletim atingia, majoritariamente, os técnicos e funcionários da LBA, bem como as classes média e alta, que contribuíam financeiramente para as obras da LBA.

Com o fim da guerra e do Estado Novo em 1945, iniciava-se um novo período na história da LBA, com transformação no escopo de suas atividades. Ficava, a partir de então, previsto nos estatutos da LBA que sua ação seria especificamente direcionada para o amparo à maternidade e à infância. Saíram definitivamente de cena os ex-combatentes e suas famílias. Essa mudança também se alinhava à propositura constitucional do dever do Estado na proteção à maternidade e à infância, pois a nova Constituição, aprovada em 1946, trazia, de forma inédita, o preceito de que a responsabilidade pela proteção à maternidade e à infância era do Estado brasileiro (Côrtes, 2012). O Boletim, em 1947, indicava o propósito da atuação da LBA no período pós-guerra.

O combate à mortalidade infantil, através de medidas práticas que assegurem maior assistência às gestantes pobres e efetivo amparo aos lactentes, mediante a difusão de postos de puericultura, lactários, maternidades e creches assumem importância fundamental nessa patriótica campanha em que a LBA se vem empenhando (Boletim da LBA, set. 1947, p.8).

É possível afirmar que a LBA e seu Boletim procuraram estar em consonância com o momento do país. O período 1955-1960 ficou marcado por um debate na instituição acerca de 
seu modelo assistencial, engendrando transformações durante as presidências de Raymundo Martagão Gesteira e Mário Pinotti, médicos renomados, tendo na presidência da República também um médico - Juscelino Kubitschek. O caráter sanitário-desenvolvimentista das práticas assistenciais é acentuado por meio de cursos de puericultura e pela construção de centenas de postos de puericultura pelo país, tendo em vista uma orientação de Juscelino de interiorização da saúde e da modernidade que ele propunha a todo o país. Entre 1958 e 1960, Mário Pinotti acumularia os cargos de presidente da LBA e ministro da Saúde, alinhando objetivos e ações do governo e da LBA.

Nesse sentido, analisamos as páginas do Boletim almejando perceber as representações sobre maternidade e sobre o parto veiculadas nos artigos e nos textos sobre as campanhas empreendidas pela LBA, especialmente na batalha contra a "ignorância" e o "atraso".

\section{Ignorância e combate à mortalidade infantil}

A ideia de que após a Segunda Guerra Mundial e até meados da década de 1960 o Brasil viveu um período áureo, seus "anos dourados", decorre de um forte processo de modernização da sociedade brasileira, bem como da experiência democrática. Sob diferentes aspectos, o Brasil parecia "dar certo". ${ }^{6}$ No entanto, a sociedade brasileira precisava ainda lidar com o flagelo da mortalidade infantil, cujo elevado índice chocava-se com a proposta de construção de uma sociedade moderna e civilizada, evidenciando que a modernidade e suas benesses não alcançavam todos. Segundo dados de Bertolli Filho (2011, p.46), em 1955 os índices de mortalidade infantil eram alarmantes nas capitais brasileiras, sendo o mais elevado em Natal, com 421,3 mortos por mil nascidos vivos, seguido por Salvador $(353,5)$ e Teresina $(325,3)$. Os mais baixos números eram de Porto Alegre $(100,9)$, Niterói $(96,9)$ e São Paulo $(86,5)$, denotando também as desigualdades entre as regiões brasileiras.

Ante o discurso modernizante, a mortalidade infantil era exponencialmente atribuída à ignorância, especialmente materna, e às posturas consideradas arcaicas. No imaginário brasileiro da época predominava a exaltação da vida urbana, enquanto o rural estava bastante associado às práticas e costumes tradicionais e, portanto, ao arcaico. Barbosa (2017, p.102) fez oportuna análise do surgimento da LBA e de como coadunava-se a um ideário do período, isto é, "crendo na possibilidade de reformar o caráter humano, os profissionais aliados ao projeto modernizador do Estado Novo viam nas famílias a possibilidade de projetar um novo cidadão". Desse modo, o embate principal que se travava era entre o arcaico e o moderno, o Brasil atrasado, rural e agrário devia dar lugar ao Brasil moderno, urbano, industrial. ${ }^{7}$

esse é um tempo de grandes transformações para o país, que altera de forma profunda e decisiva sua 'vocação' e lhe dá uma nova face, desde muito almejada: uma face urbana, industrial, moderna e civilizada, não mais colonizada e atrasada, finalmente ... Ao menos, era isso o que movia o pensamento e ação de grande parte das elites políticas, econômicas e culturais do período que, mesmo estando em disputa - quanto ao como e em que ritmo e direção esse processo devia seguir -, estavam de acordo em relação à tarefa de 'organizar' o Brasil, acreditando que, para tanto, o Estado tinha um papel incontornável a cumprir (Gomes, 2013, p.42; destaques no original). 
Assim, a oposição entre moderno e arcaico encontrou frutífero campo nas reflexões sobre a maternidade no período entre os anos 1940 e 1960. Para enfrentar as elevadas taxas de mortalidade materno-infantil apresentava-se como principal solução a medicalização da maternidade e do cotidiano materno-infantil.

A partir do pressuposto que tomava por causa principal da mortalidade infantil a ignorância ou negligência das mães - ainda que se percebesse a influência da má qualidade de vida, especialmente nas classes trabalhadoras -, a solução preferencial para o grave problema de tal 'desperdício de vidas' seria a difusão dos princípios da puericultura, que ensinariam todas as mulheres a cuidar adequadamente de seus filhos (Freire, 2009, p.140; destaque no original).

A ignorância das mães era apontada como fator preponderante para a causa de tantas mortes de recém-nascidos e bebês até o primeiro ano de vida. A batalha contra a "ignorância" materna seria travada por médicos, jornalistas, voluntários da assistência social, bem como setores ligados ao poder público. É possível afirmar que a LBA e seu Boletim comungavam da ideia de que o desconhecimento de preceitos médico-científicos modernos por parte das mães era o principal elemento fomentador da mortalidade infantil. Assim, publicavam no sentido de promover a "luta contra a ignorância", cuja representação podia se dar por meio de diversos elementos, tanto o atraso em áreas médicas quanto a presença sistemática de conselhos e orientações oriundos do conhecimento popular.

É indispensável, portanto, através de uma sistemática campanha educacional, lutar contra o terrível mal que é a 'ignorância', derrubando preconceitos, incutindo noções básicas, orientação, esclarecimentos e conselhos, no sentido de que as crianças possam nascer e crescer sadias e que possam apresentar condignas condições de vida. É a grande finalidade da puericultura (Boletim da LBA, jan. 1951, p.32; destaque no original).

É pertinente destacarmos o processo de expansão do papel e das funções dos médicos, principalmente junto às mulheres e à maternidade. Além disso, há a consolidação desse papel como inalienável, ou seja, como uma posição que ninguém mais poderia desempenhar a não ser o próprio médico. Em vista disso, é evidente que se tivesse reservado um lugar especial para a mulher-mãe, como um agente treinado das modernas práticas médicocientíficas: "[A mãe] Deve ter sempre presente que não é médica, que ignora a medicina, que não sabe fazer um diagnóstico, que não pode optar, com conhecimento de causa, por tal ou qual terapêutica. É excelente que ela tenha consciência de sua incapacidade nesse particular" (Boletim da LBA, nov. 1951, p.9). Médicos, higienistas e assistentes sociais passavam a ditar as regras para a medicalização e modernização da maternidade, criando a figura da "mãe-cientista" para cuidar do recém-nascido. A medicina científica sai dos hospitais e salas de cirurgias e invade os lares. ${ }^{8}$

O Boletim é bastante claro ao dizer que a gestante deve colocar-se sob a vigilância do médico. É ele quem ditará as medidas para a sua conduta correta. Recordamos Michel Foucault (1979, p.80), que procurou demonstrar que "o controle da sociedade sobre os indivíduos não se opera simplesmente pela consciência ou pela ideologia, mas começa no corpo, com o corpo. Foi no biológico, no somático, no corporal que, antes de tudo, investiu 
a sociedade capitalista". Assim, a ação de controlar os corpos femininos propiciaria um controle sobre a maternidade e a infância.

A gestação é um fenômeno fisiológico, porém, malgrado ser um fenômeno de ordem fisiológica, ela não dispensa a assistência precoce e contínua do obstetra. É necessário repetir que a gestante, desde o início da sua gestação, deverá colocar-se sob a assistência e vigilância do seu médico (Boletim da LBA, mar. 1951, p.11).

É possível percebermos, em consonância com Martins (2000), que a classe médica precisava aumentar o alcance de seus preceitos. Segundo a autora, "a partir do século $\mathrm{XX}$ os médicos perceberam que os seus conselhos quanto à saúde e ao bem-estar das mulheres e das crianças não surtiriam efeito se o seu público-alvo não fosse ampliado consideravelmente" (p.216). Nesse mesmo sentido, Luca (2012) chama atenção que médicos, psicólogos e outros profissionais passam, com maior frequência, a contribuir para publicações periódicas de grande circulação, como as revistas femininas. A figura do médico substituíra a do padre no papel de conselheiro das famílias, ${ }^{9}$ e mesmo quando não era possível o contato tão próximo, este se dava por meio das revistas, periódicos, programas de rádio, cursos etc.

Consolida-se, portanto, a figura da mãe amparada pela ciência e pelos modernos aparatos científicos. O que o Boletim, como um propagador dessas perspectivas, enseja apresentar que "a mãe deve ser enfermeira e, na generalidade dos casos, possui ou adquire rapidamente as qualidades de uma excelente enfermeira; mas nem por isso é médica" (Boletim da LBA, nov. 1951, p.9), enfatizando a primazia do médico.

No que diz respeito à ação da LBA, a luta contra a ignorância foi sintetizada pela contínua promoção de conhecimentos básicos de puericultura às mães e futuras mães brasileiras por meio de cursos. O Boletim salientava que "a finalidade dos Cursos de Puericultura é instruir as mães, como devem criar bem os filhos, a fim de torná-los sadios e fortes" (Boletim da LBA, abr.-maio 1951, p.8). E mais claramente:

O problema só pode ser resolvido se for encarado de frente. Façamos a puericultura individual, disseminando por todo o Brasil centros de puericultura onde o técnico oriente as mães na sua nobre missão de criar filhos sadios. ... Finalmente, façamos a puericultura social, em larga escala, instituindo cursos elementares de puericultura para as meninas dos últimos anos das escolas primárias, e cursos médios para as ginasianas, normalistas e senhoras da sociedade (Boletim da LBA, out. 1951, p.4).

O objetivo maior da divulgação de tais pressupostos nas páginas do Boletim é, sem dúvida, pôr fim à "ignorância" e à influência negativa dos costumes e hábitos tradicionais, uma "batalha" que já se desenrolava desde as primeiras décadas do século XX, como analisado por Freire (2009). ${ }^{10}$ Estabelecia-se uma declarada contenda contra os saberes populares, apontados como traços de um atraso que caracterizava o Brasil e como grandes vilões no tocante às mortalidades infantil e materna.

Estabelecendo uma clivagem entre o saber médico e o saber leigo das mães, os médicos desqualificaram qualquer prática ou experiência que não tivesse fundamento científico e profissional. As mães são vistas com desconfiança e culpabilizadas pela mortalidade infantil, mas também são merecedoras da atenção e dos cuidados médicos. Como as 
crianças, as mães precisam ser educadas e os médicos atribuem a si essa tarefa por meio de um conjunto de práticas e de uma metodologia própria cujo objetivo é, em síntese, a normalização da maternidade (Martins, 2008, p.143).

Concomitantemente ao fortalecimento social da opinião médica, ocorre o enfraquecimento da relevância atribuída ao conhecimento popular, tradicional. No entanto, cabe apontar que a interposição do conhecimento médico-científico sobre o popular/tradicional não se deu sem conflitos e resistências, tanto é que tais esforços são empreendidos desde os primeiros anos do século XX, conforme apontou Freire (2009), e avançam até os anos 1960.

Percebe-se que, nessa luta contra a "ignorância" e os velhos costumes, a LBA já tinha identificado, ao menos desde 1947, um inimigo a ser combatido. Tratava-se das parteiras, aparadeiras e "curiosas", isto é, mulheres que auxiliavam e amparavam as gestantes durante a gravidez e no momento do parto. Em geral, as "curiosas" eram mulheres próximas às parturientes, podendo ser vizinhas, familiares ou mesmo profissionais não diplomadas na área. O Boletim publicou frequentemente sobre elas, e não lhes poupava responsabilidades.

A 'curiosa', a 'comadre', a 'parteira por palpite', saída das mesmas baixas esferas, comete monstruosidades sem nome e daí nascerem crianças com anomalias orgânicas, como podem ser vistas, aos grupos, nas plataformas das estradas de ferro e nos postos de parada, dos 'ônibus' interestaduais (Boletim da LBA, set. 1947, p.22; destaques no original).

Para impedir que as "curiosas" atuassem junto às gestantes, a LBA agia, segundo o Boletim, por meio de extensas campanhas para que as gestantes procurassem se aconselhar exclusivamente com médicos. Essa ação não se mostrou eficaz de imediato, mas seguiria sendo utilizada, uma vez que são recorrentes, ao longo do período estudado, as publicações sobre o aconselhamento exclusivo da gestante com o médico. A LBA também procurou agir no sentido de educar as mulheres que atendiam as parturientes, fazendo com que elas aprendessem noções de puericultura e cuidados obstétricos. Em 1947, o Boletim já noticiara que a Comissão Estadual da LBA no Rio de Janeiro estava organizando o Serviço de Higiene Pré-natal (SHPN) para orientar mães, futuras mães e também aquelas que auxiliavam as gestantes. Dentre diversas funções, o SHPN ficaria responsável pela aproximação da LBA com as "curiosas", e seu estatuto sintetizava a ação da LBA nessa questão.

IX - O SHPN organizará um registro de todas as curiosas da área de sua jurisdição, ministrando-lhes noções práticas de emergência utilizando as menos incapazes na cooperação com o Centro de Saúde e proibindo a atuação das julgadas inaptas.

XI - As curiosas obrigar-se-ão:

(a) a atender unicamente ao parto das gestantes matriculadas no SHPN que, para isso, fornecerá licença expressa em cada caso;

(b) a encaminhar ao SHPN as gestantes de seu conhecimento;

(c) a notificar os partos por elas assistidos;

(d) a frequentar, com a regularidade que lhes for determinada, o Posto do SHPN, para efeito de sua instrução e controle;

(e) a carteira de saúde expedida pelo serviço competente do Serviço Médico Social da Sede. 
XII - O SHPN fornecerá, gratuitamente, às curiosas sob controle, pacotes obstétricos contendo material de emergência indispensável ao trabalho de parto (Boletim da LBA, jun.-jul. 1947, p.6).

Pela atuação do SHPN, a LBA esperava colocar sob sua orientação as parteiras e curiosas, impondo-lhes uma série de medidas e restrições às suas atividades. Na edição seguinte, agosto de 1947, o Boletim destacava que o SHPN investia em outra abordagem para aproximar as curiosas das práticas modernas da puericultura, incluindo remuneração pelos serviços delas, tendo em vista as dificuldades encontradas em um encaminhamento voluntário.

Temos encontrado dificuldades no controle das curiosas. A princípio, julgavam elas que o Serviço da LBA lhes iria ser um concorrente e, como tal, procuravam desviar as pacientes dali. Outras calculavam que, após vinte ou trinta anos de prática, não precisariam mais ouvir aulas e nem se sujeitavam a matrículas em tais locais. Queremos informar-lhes que tudo temos feito para captar simpatias, pois as atendemos quando necessitam, fornecendo-lhes remédios, muitas das vezes dinheiro para passagem, mas, mesmo assim, ainda é pouco o número das que são simpatizantes ao Serviço. Estabelecemos e resolvemos propor à Direção da LBA pagar Cr\$2,00 em cada gestante que enviarem ao Serviço e, no fim do ano, um prêmio à que maior número de gestantes matricular (Boletim da LBA, ago. 1947, p.3).

É relevante notarmos que não está previsto apenas o treinamento dessas mulheres, mas, especialmente, um controle exercido sobre elas. O combate à ignorância, personificada nas "curiosas", justificava-se, segundo o Boletim, diante da elevada mortalidade maternoinfantil no parto ou nos primeiros dias e semanas do puerpério. O Boletim, já na década de 1960, insistia sobre a estreita ligação entre as curiosas e a mortalidade, o que ocasionava um franco prejuízo ao Brasil.

as parturientes do Brasil cujo número atinge anualmente a 'dois milhões e seiscentos mil', sendo que, dessas, 'dez mil e quinhentas' sucumbem ao peso da parturição. ... A mulher brasileira, no momento da parturição, está completamente desamparada, entregue à sanha caritativa, porém nefasta, das 'curiosas ignorantes' e 'farmacêuticos inconscientes' (Boletim da LBA, jul.-set. 1961, p.18; destaques no original).

Nesse discurso combativo à atuação de parteiras não diplomadas, avulta-se, o que já vínhamos apontando, uma sobreposição eficazmente organizada da medicina moderna aos conhecimentos, práticas e costumes tradicionais, bastante personificados nessas mulheres das comunidades. Nas palavras de Mott (1999, p.25):

A imagem da parteira como mulher ignorante, analfabeta, sem moral, responsável pela morte de mães e recém-nascidos devido à falta de qualificação profissional, é encontrada não apenas na literatura médica brasileira do século XIX, como também na de vários países, tendo sido inclusive incorporada por historiadores e sociólogos do século XX.

Martins (2000) ressalta que os cuidados com a mãe durante e após o parto são historicamente competências femininas, sendo os médicos chamados apenas em casos de risco iminente à vida da mãe. Para a autora, essa relação conflituosa sobre a arte de partejar é em verdade "muito mais o resultado de uma relação de força do que simplesmente a superação do obscurantismo pelo progresso do conhecimento médico" (p.67). O crescimento 
do conhecimento técnico-científico, em meados do século XIX, também se estendeu sobre a maternidade e o momento do parto. Assim, do ponto de vista de campos sociais de atuação, a medicina científica passou a desacreditar os conhecimentos populares. É possível apontar que há uma disputa por campos de atuação cujo objetivo vai além do bem-estar materno infantil ou o progresso da "raça brasileira", ${ }_{11}^{11}$ como alardeavam cronistas da época. Tratando-se, propriamente, de uma disputa por capital social e por ocupação de um campo, no sentido proposto por Bourdieu (2001), de um conjunto de relações de força objetivas que são impostas a todos os que entrem ou atuem nesse campo. A esse respeito, o Boletim evidencia em suas páginas, no ano de 1951, a sobreposição que se dá entre a influência tradicionalmente exercida pelas parteiras e aquela que passam a exercer os médicos.

O médico vai dar sua última palavra. Ou uma parteira? Ou uma curiosa? A verdade é que a situação econômica de muitas famílias não permite o chamado de médico especializado. A parteira, e sobretudo a 'curiosa', aí estão casos que exigem precauções, quanto à idoneidade e [à] competência. Mesmo assim, e em tal caso, convém ter sempre em vista um médico, para a hipótese de sobrevir qualquer surpresa desagradável (Boletim da LBA, nov. 1951, p.6; destaque no original).

Fica evidente na supracitada passagem que, para o Boletim, bem como para a LBA, é o médico quem deve sempre dar a última palavra, reforçando a posição do médico como autoridade máxima nesse assunto. Fez-se igualmente presente a perspectiva de que a mãe deveria ser sempre auxiliada, preferencialmente pelo médico, uma vez que, em paralelo ao processo de educação das mulheres para novas funções maternais, deu-se um processo de culpabilização da mãe pela mortalidade infantil.

Só erros alimentares oriundos do desconhecimento por parte dos pais, dos princípios higiênicos da alimentação da criança, erros causadores das 'diarreias infantis' ou perturbações do intercâmbio nutritivo, contribuem com a cifra aproximada de $40 \%$ do obituário do primeiro. E, o que é digno de ser posto em destaque é o fato de que esses erros, ligados à alimentação da criança, poderão ser evitados através de ensinamentos e orientação das mães neste sentido (Boletim da LBA, abr.-jun. 1952, p.11; destaque no original).

É importante ressaltarmos que, de acordo com o Boletim da $L B A$, a maior preocupação da instituição, no conjunto de esforços para o combate à mortalidade infantil, era a proposição de uma educação tida como moderna das mães brasileiras e a luta contra a ignorância, representada, principalmente, pelo combate às práticas tradicionais do partejar e do maternar.

Seria preciso, pois, que as mulheres fossem preparadas para o seu papel de mãe. Em consequência, no plano preventivo é necessário, durante os últimos anos escolares, realizar um trabalho construtivo e preparar as jovens para o seu futuro papel de mães de família. O ensino de prendas domésticas, compreendendo a puericultura, deveria ser obrigatório em todas as escolas. Além disso, seria oportuno desenvolver a iniciativa tomada por certas indústrias e empresas que organizam cursos de ensino de atividades domésticas (Boletim da LBA, dez. 1959, p.19-20). 
As discussões acerca da educação das mulheres eram intermediadas pela concepção de uma "natureza feminina" direcionada ao lar e à maternidade. A ideia de tal "natureza feminina" também esteve em debate quando se desenvolveu, no contexto de substituição de práticas antigas por "modernas", um forte apelo ao parto hospitalar, em oposição ao parto domiciliar. A transferência do parto da casa para o hospital engendrara debates morais e científicos, além de um controle mais efetivo por parte da medicina moderna.

\section{Parto hospitalar e a medicalização da maternidade}

No percurso de expansão da modernidade para os domínios da saúde e do bem-estar, os médicos passaram a ser considerados figuras centrais no processo de preparo e cuidado das novas vidas que vêm ao mundo. O Boletim da LBA procurou evidenciar a necessidade aguda de cientifizar e medicalizar o parto, preferencialmente repelindo as parteiras "ignorantes"; quando impossível, educando-as dentro dos parâmetros médico-científicos considerados adequados.

O processo de medicalização e patologização do corpo feminino se deu, sobretudo, em função da reprodução humana, como apontaram Martins (2000) e Vieira (2002). O parto então desponta como um momento crucial no qual a medicina incide sobre vidas e corpos femininos. Martins enfatizou que "o conhecimento do mecanismo do parto teve grande impacto na extensão do controle médico sobre o corpo feminino. A obstetrícia tornarase um estudo preciso, quase matemático, ao transformar o corpo materno num espaço analisável, mensurável e passível de intervenção" (Martins, 2000, p.106).

Segundo Vieira (2002, p.60; destaque no original), "a medicalização da maternidade surge baseada no estereótipo da 'natureza feminina', em uma época em que ser mãe transforma-se de destino em dever patriótico". A representação da maternidade como parte indelével da essência feminina tornou-se bastante vigorosa nas primeiras décadas do século XX, assim como ganhara nuances de "missão divina" e "ato patriótico por excelência". Tendo em vista que a natureza feminina, bem como a masculina, eram claramente definidas, os papéis sociais que homens e mulheres deveriam desempenhar também eram bastante precisos.

Ser mãe, esposa e dona de casa era considerado o destino natural das mulheres. Na ideologia dos Anos Dourados, maternidade, casamento e dedicação ao lar faziam parte da essência feminina; sem história, sem possibilidade de contestação. A vocação prioritária para a maternidade e a vida doméstica seriam marcas de feminilidade, enquanto a iniciativa, a participação no mercado de trabalho, a força e o espírito de aventura definiriam a masculinidade (Pinsky, 2010, p.609-610).

A construção de hospitais e maternidades foi uma das principais ações no contexto de expansão dos cuidados e das noções de higiene e saúde pública. Trata-se de um período da história da saúde no Brasil que pode ser caracterizado como "sanitarismo desenvolvimentista" (Escorel, Teixeira, 2008), uma vez que se orientava pelo pressuposto de que o grau de desenvolvimento econômico de um país ou de uma região dependia, fundamentalmente, do nível de saúde da população, sendo os investimentos em saúde pública, portanto, justificados em nome do progresso e desenvolvimento do Brasil. ${ }^{12}$ Como 
apontou Martins (2000, p.81), “a percepção de que o crescimento populacional e a riqueza das nações dependiam das boas condições de saúde foi de fundamental importância para o processo de profissionalização e de legitimação do saber médico".

Nesse período, a ginecologia, a obstetrícia, a pediatria e a puericultura se constituíram em especialidades médicas e forneceram a justificativa científica para o discurso em defesa da criação de maternidades, entendidas como um espaço hospital destinado exclusivamente ao parto e ao cuidado com as puérperas e as crianças (Barreto, 2015, p.186).

Procurou-se associar a construção de hospitais e maternidades e a paulatina transferência dos partos para esses espaços a um processo civilizatório e modernizador do Brasil. Desse modo, entendemos que a divulgação e a defesa do parto hospitalar faziam parte do escopo de atuação da LBA e, portanto, estavam presente nas páginas de sua publicação oficial. O Boletim advogava em prol do parto hospitalar, como, por exemplo, em um texto de 1951: "Um hospital bem montado e dirigido possui muitas vantagens sobre o domicílio. Talvez seja mais barato, é muito mais conveniente e, se se apresentar alguma complicação, oferece outras garantias, tanto para a mãe como para a criança" (Boletim da LBA, set. 1951, p.14). No mesmo texto, a publicação apresenta ainda instruções de como deveria ser o quarto, caso não seja possível ir ao hospital, destacando uma série de medidas "para assegurar uma assepsia mais rigorosa".

A mortalidade infantil representava uma forte preocupação social, conforme já apontado, mas a mortalidade materna também atraía atenção, tanto pelas cifras que acumulava quanto pela importância social da maternidade. Em 1961, o Boletim ocupou-se de tal premissa, a fim de enfatizar a importância do parto hospitalar, acompanhado pelo médico.

A mortalidade materna no Brasil representa um coeficiente 5,3 por mil refletindo uma situação calamitosa. Sabemos a influência que têm, nesse problema, os fatores extramédicos chamados econômico-sociais, responsáveis pelo baixo nível de vida da maior parte da população (falta de educação e instrução, de transporte, alimentação insuficiente e defeituosa, ausência de técnicos etc.). Tais fatores agem, de maneira acentuada, na ceifa das mulheres quando no desempenho da sua atribuição precípua de perpetuar a espécie. Se os fatores médicos fossem atendidos com interesse, inteligência, critério, sinceridade, firmeza e devotamento poderiam de maneira efetiva modificar, de forma ponderável, o panorama lastimável que se desenrola ante nossos olhos (Boletim da LBA, jul.-set. 1961, p.18).

O Boletim salienta que os fatores sociais seriam mais difíceis de dirimir, ressaltando uma necessária atenção aos fatores médicos, executável de forma mais contundente no ambiente do hospital. É possível compreender que, ao longo das décadas de 1950 e 1960, o Boletim enfatizou a necessidade de o parto se dar no ambiente hospitalar. Em passagem de 1961, a publicação avaliou que o parto em casa não ofereceria bons resultados; no entanto, é bastante oportuno salientarmos que, no posicionamento tomado pela publicação, a decisão sobre o parto se dar no ambiente dos hospitais ou no lar passara a não caber à mulher ou à família. Segundo o Boletim, caberia ao serviço social estudar quais residências são capazes de abrigar o parto, reforçando uma perspectiva de controle externo sobre o parto e sobre a própria parturiente. 
Ainda que em tese sejamos favoráveis ao empreendimento [parto em domicílio], em face da realidade brasileira, tal iniciativa não pode nem poderá dar os resultados proclamados e esperados ... só deverão ser assistidas em residência as gestantes selecionadas pelo Serviço Pré-Natal, cujos domicílios e condições de família, estudados pelo serviço social, a isso recomendem (Boletim da LBA, out.-dez. 1961, p.12).

Indicativo também desse entendimento da LBA, em 1963, uma das medidas aprovadas no quarto Seminário Regional da LBA, realizado em Vitória, Espírito Santo, foi que se deveria recomendar "sempre que possível o parto hospitalar" (Boletim da LBA, jul.-set. 1963, p.34). Isto é, o parto hospitalar passa a figurar como prerrogativa no escopo das ações da LBA, e não como apenas uma possibilidade.

O processo de transferência dos partos para o ambiente hospitalar remonta aos séculos XVIII e XIX, contexto no qual foi operada significativa transformação do entendimento e das funções dos hospitais, de forma geral. Até o século XVIII, os hospitais eram morredouros, ambientes para os quais acorriam aqueles que necessitavam ser assistidos física e espiritualmente no preparo para a morte. O hospital era comandado por religiosos, numa acepção cristã de caridade. O que transformou os hospitais, medicalizando-os e tornando a medicina também hospitalar, foi uma grande reforma para purificá-los dos efeitos nocivos e pestilentos que ali se apresentavam. Tal modificação foi possível a partir do século XVIII e dos estudos sobre contaminações (Foucault, 2004). ${ }^{13}$ No mesmo trabalho, Foucault também procurou ressaltar que a confinação dos doentes em um mesmo lugar possibilitava o exercício mais efetivo do controle sobre eles, bem como o desenvolvimento de um processo disciplinar.

A mudança na percepção sobre os hospitais possibilitou a transformação do parto em um acontecimento hospitalar:

O período que começa nas últimas décadas do século XIX marca o início de uma campanha médica de transformação do parto num evento controlado pelos médicos e circunscrito ao espaço hospitalar; transformação esta que se efetivou somente na segunda metade do século XX, com a hospitalização do parto nos centros urbanos (Martins, 2000, p.61).

Esse processo não se deu de forma harmônica e sem embates. É possível apontarmos algumas resistências à medicalização do parto. Uma flagrante oposição a esse processo foi a mencionada disputa de poder e espaço entre médicos e parteiras, tanto as leigas quanto as diplomadas. Pode-se indicar também que as parturientes resistiam à presença do médico e os próprios médicos resistiam a participar diretamente do parto. A relutância de parturientes e médicos originava-se na mesma raiz: a misoginia nas representações sobre o corpo e a sexualidade femininas.

Partindo de princípios aristotélicos sobre o masculino e o feminino, a medicina, até os séculos XVIII e XIX, percebia o feminino como masculino malformado (Martins, 2000; Vieira, 2002). O momento do parto era inapropriado aos homens em função dos princípios maléficos que o sangue feminino traria em si (Del Priore, 1994; Diniz, 1996). Por tais motivos, a parturição foi sempre atividade feminina. A natureza feminina apontada como diabólica, pecadora, instigava as representações sobre bruxarias e feitiçarias, especialmente sobre as parteiras no momento do parto. ${ }^{14}$ 
A incidência de preceitos religiosos sobre o corpo feminino é bastante significativa e longeva. A ideia da mulher naturalmente pecadora formulara-se a partir da concepção cristã sobre o pecado original e o banimento do jardim do Éden. Em função de tais concepções se deu o entendimento de que um parto doloroso era necessário para que a mulher expiasse os pecados de uma concepção pecaminosa (Diniz, 1996). A passagem bíblica do Gênesis foi, usualmente, referenciada como uma legitimação para as dores do parto e o sofrimento feminino, bem como para o distanciamento do conhecimento médico: "Ele disse à mulher: 'Farei com que, na gravidez, tenhas grandes sofrimentos; é com dor que hás de gerar filhos. Teu desejo te impelirá para teu homem, e ele te dominará"' (Gênesis, 3:16 citado em Diniz, 1996, p.117).

A permanência e a dificuldade de abandonar tais preceitos podem ser percebidas ainda na década de 1950. No Boletim da LBA encontramos passagens que discutem o parto sem dor, sob os prismas médico e religioso. Entretanto, é necessário, de antemão, pontuarmos a significativa aproximação entre a Igreja católica e a LBA. Nesse sentido, desde a reforma institucional de 1946, a Ação Social Arquidiocesana passou a ocupar um dos cargos de vicepresidente na LBA. Mais significativamente, ao longo do ano de 1963, sob a presidência da primeira-dama Maria Thereza Goulart, padre Joaquim Horta foi diretor-superintendente da entidade, denotando franca aproximação entre as duas instituições. Sem contar que parte do corpo institucional da LBA era formado por senhoras voluntárias, remetendo à tradição católica do engajamento das mulheres de elite em ações filantrópicas. ${ }^{15}$

Frequentemente foram publicados textos no Boletim com clara orientação católica. Em 1951, foi publicada a primeira passagem sobre o debate acerca do parto sem dor. As questões que orientavam tal contenda concerniam tanto a um dilema moral-religioso quanto às novas técnicas de anestesia e analgesia.

O problema do parto sem dor está em foco, e a Igreja se pronuncia a respeito. Os médicos que se opõem à analgesia obstétrica fazem valer dois argumentos, o primeiro de ordem médica: a analgesia obstétrica nunca é absolutamente inofensiva para a criança. Os partidários do novo método replicam: (a) que o Papa, se desaconselhou a terapêutica, não a proibiu formalmente; (b) que, se a anestesia (o sono) é muitas vezes nociva, a analgesia (insensibilização), bem administrada, não só não o é, mas muitas vezes se torna salutar para a criança (Boletim da LBA, jun. 1951, p.3).

O Boletim invoca a chancela do papa, líder da Igreja católica, para desenvolver seus argumentos. O texto é concluído com uma interrogação retórica: "Estará resolvido o problema do parto sem dor? Temos nossas dúvidas ... Em vão se há de desmentir as palavras divinas: 'Parirás com dor'” (Boletim da LBA, jun. 1951, p.3), retomando a condenação lançada sobre Eva e suas descendentes no jardim do Paraíso.

A referência ao pontífice reaparece em 1956, quando o Boletim destaca que o papa se pronunciara a respeito do parto sem dor ao se dirigir a ginecologistas italianos. As palavras de Pio XII apresentadas no Boletim são: "O cristianismo não interpreta o sofrimento e a Cruz de maneira puramente negativa. Se a nova técnica poupa as dores do parto ou as ameniza, a mãe pode aceitá-lo sem nenhum escrúpulo de consciência" (Boletim da LBA, jan.-mar. 1956, p.28). Pio XII também teria se manifestado sobre uma possível contradição entre a escritura sagrada cristã e as novas descobertas da ciência: 
Deus não queria proibir e não proibiu aos homens procurar e utilizar todas as riquezas da criação, fazer avançar passo a passo a cultura, tornar a vida neste mundo mais suportável e mais bela, aliviar o trabalho e a fadiga, a dor, a doença e a morte prematura, de dominar a terra ... Do mesmo modo, disse em conclusão Pio XII, ao punir Eva, Deus não quis proibir nem proibiu às mães utilizarem os meios que tornaram o parto mais fácil e menos doloroso. Às palavras da Escritura não se devem buscar escapatórias: elas permanecem inabalavelmente verdadeiras (Boletim da LBA, jan.-mar. 1956, p.28).

Para o Boletim, era importante apresentar certo aval do líder espiritual do catolicismo sobre os embates entre ciência e religião, uma vez que o Boletim, bastante amalgamado com os valores cristãos, atuava diuturnamente para a propagação de preceitos científicos no Brasil. As palavras do Sumo Pontífice seriam retomadas em outra edição de 1956, por Otávio Rodrigues Lima, professor de clínica obstétrica na Faculdade Nacional de Medicina da Universidade do Brasil e diretor da Maternidade-Escola, para explicar o método do parto sem dor e suas implicações. Lima esclarece que a origem do método são os estudos do cientista russo Ivan Pavlov, mas ressalta que "Por conseguinte, o fato de ser baseado nas ideias de Pavlov não nos leva a considerá-lo produto da atual ciência russa" (Boletim da LBA, jul.-set. 1956, p.16). Lima é cuidadoso ao salientar que Pavlov já havia recebido em 1902 um prêmio Nobel, anteriormente ao advento do comunismo, e que o cientista teria sido depois "absorvido pelo novo regime". O comunismo e a influência russa no mundo bipolarizado da Guerra Fria também aparecem nas palavras do papa Pio XII: ${ }^{16}$

A ideologia de um pesquisador e de um cientista não é, em si, uma prova da verdade e do valor daquilo que ele encontrou e explicou. O teorema de Pitágoras, ou, para que permaneçamos no domínio da Medicina, as observações de Hipócrates, que foram reconhecidas exatas, as descobertas de Pasteur, as leis da hereditariedade de Mendel não devem a verdade do seu conteúdo às ideias morais e religiosas dos seus autores. Não são nem pagãs, pelo fato de que Pitágoras e Hipócrates eram pagãos, nem cristãs, porque Pasteur e Mendel eram cristãos (Boletim da LBA, jul.-set. 1956, p.16).

É possível compreendermos que, para além das questões médico-científicas, o que realmente se discutia eram preceitos morais, religiosos e, até mesmo, político-ideológicos materializados no debate sobre o parto sem dor. Cabe então uma breve explicação, a partir do próprio Boletim da $L B A$, do que consistia o método de analgesia para o momento da parturição.

Em primeiro lugar, a compreensão, por parte da gestante, dos diferentes fenômenos do parto, que ela deve aceitar com orgulho e como um prêmio, afastando todas as ideias de temor - e por que não dizer ideias de pavor? - que costumam acompanhar a ignorância. Aliás, isso já constitui a base do chamado método de parto natural, divulgado, desde há quinze anos, na Inglaterra, pelo Dr. Dick Read e que teve larga divulgação leiga. O que diferencia o método russo é a explicação baseada nos reflexos condicionados. A conduta do pessoal que cerca a parturiente deve ser toda especial, por constituir a 'palavra' a arma principal para a criação dos reflexos que inibem a sensação dolorosa (Boletim da LBA, jul.-set. 1956, p.16; destaque no original).

O Boletim menciona o médico inglês Dick-Read, um dos precursores das técnicas de "parto sem dor" ou "parto sem medo", e sua obra Natural childbirth, publicada em 1933, 
na qual apresentava suas ideias sobre a prejudicial influência de fatores emocionais na evolução do parto. Segundo Freddi (1973, p.110-111), Dick-Read apontara a tríade "medo - tensão - dor" como a responsável pelo desconforto e pela dor no parto; e também teria feito referência à perniciosa influência da "superstição, a civilização e a cultura influem na mulher, contribuindo grandemente para o medo e a angústia relacionados ao parto" (p.111), refutando as práticas tracionais do partejar.

Os estudos de Pavlov se desenvolveram a partir de 1920 bastante voltados para as percepções sobre os condicionamentos e reflexos condicionados. A partir de suas realizações, cientistas como Velvovski e Nikolaiev passaram a utilizar os preceitos pavlovianos tanto na terapêutica em geral como para conseguir um parto sem dor. A base dos métodos está na valorização da analgesia verbal, isto é, por comandos orais. Fernand Lamaze também realizara estudos na França sobre o parto indolor, sem recorrer a fórmulas químicas. ${ }^{17} \mathrm{O}$ chamado "parto sem dor" (accouchement sans douleur) ou método Lamaze prioriza um estado de relaxamento da parturiente, especialmente por meio da respiração.

Também nessa seara a LBA seguiu a orientação, que constava em seus estatutos, ${ }^{18}$ de trabalhar em prol da educação da mulher brasileira, visando erradicar o que entendia por "ignorância e costumes atrasados" do povo brasileiro. Desse modo, encontramos referências no Boletim da LBA da realização de cursos sobre "parto sem dor", ao molde do que já acontecia com a puericultura. Em 1952, o Boletim divulgou a realização de um "Curso Popular de Partos" em Maceió, Alagoas, cujo objetivo "era proporcionar conhecimentos mais seguros às parteiras não diplomadas, de modo a evitar-lhes irreparáveis malogros, cujas vítimas principais são quase sempre as parturientes ou seus recém-nascidos" (Boletim da LBA, jan. 1952, p.13). Em 1956, o Boletim publicou a realização em São Paulo de um curso sobre "Parto sem dor pelo método psicoprofilático". A publicação trazia também a transcrição do programa do curso:

(1) Princípio fundamental da teoria da atividade nervosa superior (duas aulas) - Dr. V. Venturini; (2) Contralidade uterina no ciclo gravidopuerperal - Dr. Domingos Delascio; (3) Influência do estado psíquico sobre a contralidade uterina - Dr. Hermenegildo Morbin; (4) Interpretação pavloviana da dor no parto. Bases do método psicoprofilático - Dr. Bernardo Blay; (5) Estudo sintético da dinâmica cortical em relação ao método psicoprofilático - Dra. Salomé Midgal; (6) Respiração e sua importância na gestação e no parto. - Dra. Salomé Midgal; (7) Equilíbrio neuromuscular - Dr. Bernardo Blay; (8) Conduta no período de dilatação - Dr. Hermenegildo Morbin; (9) Conduta no período expulsivo - Dra. Salomé Midgal; (10) Importância dos excitantes positivos e negativos. Estudo de conjunto do método psicoprofilático - Dr. Bernardo Blay; (11) Fisiopatologia córtico-visceral em obstetrícia - Dr. Domingos Delascio (Boletim da LBA, abr.-jun. 1956, p.57).

O referido curso fora patrocinado pela Regional de São Paulo do Colégio Internacional de Cirurgiões e também pela Casa Maternal e da Infância Leonor Mendes de Barros. Observando as instituições promotoras do evento e o teor do programa do curso, podemos perceber se tratar de um curso direcionado aos profissionais da área da saúde, e não às mulheres das classes populares. É importante destacarmos que os métodos e possibilidades para um parto sem dor já se desenvolviam pelo menos desde o século XIX. 
Sobre a participação do Boletim em tais debates, é oportuno ressaltarmos que a publicação da LBA se concentrou, mais do que em divulgar preceitos médico-científicos, em apresentar chancelas morais-religiosas para possíveis aplicações dos métodos já existentes de parto sem dor.

\section{Considerações finais}

Uma análise do Boletim da LBA é pari passu uma análise da estrutura e das ações da própria LBA, dado que, por se tratar da publicação oficial da maior instituição de assistência social do Brasil, o Boletim apresentava as campanhas, ações e opiniões da Legião. Espalhada por todo o território nacional, a LBA conseguia um alcance sem precedentes. Suas ações se confundiam com o próprio exercício do Poder Executivo, nas esferas nacional, estadual e municipal, em razão da atuação das primeiras-damas. A recepção dos ideais propalados pela LBA é de difícil apreensão, especialmente tomando o Boletim como fonte, posto que era organizado dentro da instituição e, servindo como veículo oficial de divulgação, não há uma crítica à atuação legionária. No entanto, é possível nele compreender os pressupostos e representações sobre papéis sociais femininos e ideais de família, que, em geral, baseavam as ações legionárias, tanto assistenciais quanto educativas.

Contudo, o que se quer ressaltar é a consolidação da hospitalização do parto e da parturiente como norma médico-social, processo que se deu no bojo de transformações mais profundas na sociedade brasileira, como a refutação de saberes e costumes tradicionais e a paulatina incorporação de elementos baseados em ditames médico-científico, chamados "modernos". Tal modernização engendrou uma sistemática medicalização da maternidade e mais especificamente do parto, entendido como um momento que requer extremo cuidado e perícia técnica, oferecidos unicamente pelos médicos.

A modernidade promovida nas páginas do Boletim da LBA é, todavia, dotada de um caráter conservador. A atuação da LBA no período em questão, podemos concluir, foi marcada por um viés higienizador e reforçador de uma norma burguesa para os padrões de comportamento. Como exemplo, podemos citar que a figura materna reclusa ao lar e devotada à família é erigida pela instituição como norma a ser seguida, e todas as situações dissonantes passam a ser apontadas como "desajustadas". ${ }^{19}$ Nesse sentido, é oportuno recordarmos que a LBA era uma instituição parcialmente financiada pelos setores industriais e do comércio, bem como significativamente influenciada por setores católicos, como apontamos.

A obstetrícia e a puericultura ganharam importância social, invadiram páginas de periódicos e ondas do rádio para atingirem os lares brasileiros e ali transformarem o maternar, tornando-o cientifizado e medicalizado. Nas páginas do Boletim da LBA, a maternidade, os cuidados com o bebê e, especialmente, o parto são compreendidos dentro do âmbito da atuação médica exclusiva, e só assim podem ser considerados modernos e civilizados, à altura da ideia de país que se almejava construir - ou apenas representar nos seus "anos dourados". 


\title{
NOTAS
}

\begin{abstract}
${ }^{1}$ Sobre o esforço de submeter o natural a uma lógica moderna e racional, é bastante oportuno apontarmos o estudo de Gilberto Hochman e Elizabete Kobayashi (2015) acerca da patologização do corpo natural e seus odores, que encontrava, no período estudado (1945-1964), como contrapartida e solução a industrialização da saúde e higiene por meio de sabonetes, cremes dentais e enxaguatórios bucais. A modernização caminhava pari passu a subordinação do corpo natural à ciência, ao artificial.
\end{abstract}

2 Para aprofundamento no tema da convocação e recrutamento dos brasileiros que compuseram a FEB, ver Ferraz (2012).

${ }^{3}$ Os estatutos da LBA previam que a presidência da instituição fosse ocupada pela primeira-dama do país; no entanto, em algumas ocasiões, tal preceito não se cumpriu. Darcy Vargas foi a primeira presidente e voltou ao cargo em 1951. Carmela Dutra ocupou a presidência de honra, não se convertendo em presidente efetivamente, e Sara Kubistchek não participou da LBA, atuando em outras instituições. Eloá Quadros e Maria Thereza Goulart também assumiram a presidência da instituição enquanto seus maridos ocupavam a chefia do Executivo federal.

${ }^{4}$ Sobre o Boletim da LBA - Especial para os expedicionários, Barbosa (2017) procedeu uma análise mais pormenorizada dessas edições, bem como a atuação da LBA e do Boletim no contexto do esforço nacional de guerra.

${ }^{5}$ O conjunto de edições do Boletim da LBA disponíveis para análise é lacunar, em função também de que ainda não se procedeu a um devido inventário e processo arquivístico do acervo da LBA até então depositado no Arquivo do Ministério do Desenvolvimento Social em Brasília.

${ }^{6}$ Sobre essa temática, constitui rica contribuição historiográfica o volume Olhando para dentro, 1930-1964, organizado por Angela de Castro Gomes (2013) e integrante da coleção História do Brasil Nação (18082010), organizada por Lilia Moritz Schwarcz.

${ }^{7}$ Gomes (2013) enfatiza que cidades como Goiânia e Brasília e rodovias como a Belém-Brasília materializam bem o que se sonhava e vivia de experiência moderna.

${ }^{8}$ Um exemplo desse processo de cientifização é encontrado em 1957: “O exame das fraldas é muito simples. Se uma gota de cloreto de ferro a $10 \%$ caída numa fralda ainda molhada se tornar verde-escura, isso indicará a presença de fenilalanina no sangue" (Boletim da LBA, jul.-set. 1957, p.55).

${ }^{9}$ Segundo Costa (1999, p.77), citando estudos de Gilberto Freyre, "o confessor e o filho-padre foram sendo substituídos por essa figura carinhosa e firme, doce e tirânica, o médico da família".

${ }^{10}$ Freire (2009) analisou revistas femininas nas duas primeiras décadas do século XX, ressaltando o destaque que a puericultura alcançava e o desenvolvimento de um discurso maternalista, evidenciando a necessária participação das mulheres-mães na formação da nação. Em sua obra, em função de suas fontes, Freire acabou por ressaltar uma relação mais próxima da medicina com as mulheres de elite (e letradas), até mesmo como um primeiro passo na propagação da "maternidade científica". Três décadas mais tarde, o Boletim, e a própria LBA, engajavam-se mais tenazmente no processo de expansão da cientificidade do maternar às classes mais populares, por isso a promoção de campanhas populares, cursos e concursos de robustez com premiação em dinheiro.

${ }^{11}$ As discussões sobre a "raça brasileira" estiveram na primeira ordem durante o final do século XIX e o início do XX. As leituras trazidas da Europa sobre as diferenças entre as "raças" branca e negra eram apropriadas com suas peculiaridades pelos intelectuais brasileiros, como demonstrou Schwarcz (1993). As ideias de que o aprimoramento da raça seria possível pelo cuidado e pelo controle desenvolvidos sobre a população eram bastante comuns.

${ }^{12}$ Em 1957, o presidente da LBA, Mario Pinotti, lança um projeto para construção de um posto de puericultura em cada município brasileiro, difundindo e interiorizando os preceitos médico-científicos.

${ }^{13}$ Com a teoria microbiana das doenças (1864) de Louis Pasteur, o desenvolvimento de vacinas se fortaleceu, consolidando os trabalhos e reflexões sobre a profilaxia das doenças.

${ }^{14}$ Diniz (1996) apresenta análise sobre as representações das parteiras como bruxas e adoradoras do Diabo; Mott (1999) refletiu sobre os embates entre médicos e parteiras.

${ }^{15}$ Mott (2001) apresenta as relações entre a benemerência feminina, especialmente a católica, e as ações de assistência social no Brasil.

${ }^{16}$ Pio XII decretara em 1949 a excomunhão dos católicos que apoiassem, divulgassem ou votassem em membros de partidos comunistas ou ligados ao comunismo. 
${ }^{17}$ Desde o fim do século XVIII foram apresentadas técnicas e possibilidades para amenizar ou extinguir a dor no momento do parto. Cesbron (2008) aponta a utilização de óxido nitroso, éter e clorofórmio, entre outros, para a analgesia ou anestesia. $\mathrm{O}$ autor também aponta efeitos nocivos e desastrosos decorrentes da utilização desses compostos químicos.

${ }^{18}$ Os estatutos reformados da LBA foram publicados no Boletim (n.18 e 19) em 1946.

${ }^{19}$ No que tange às famílias e, principalmente, à infância, a LBA atuou no sentido de normatizá-las aos padrões burgueses. Na publicação, o conceito de família desajustada, em geral, referia-se à família sem a figura paterna ou na qual a mãe ausentava-se do lar para trabalhar.

\section{REFERÊNCIAS}

BARBOSA, Michele Tupich.

Legião Brasileira de Assistência (LBA): o protagonismo feminino nas políticas de Assistência em tempos de guerra, 1942-1945. Tese (Doutorado em História) - Universidade Federal do Paraná, Curitiba. 2017.

BARRETO, Maria Renilda Nery.

Dar à luz no Rio de Janeiro da Belle Époque: o nascimento das maternidades, 1870-1920. In: Sanglard, Gisele et al. (Org.). Filantropos da nação: sociedade, saúde e assistência no Brasil e em Portugal. Rio de Janeiro: FGV Editora. p.185-202. 2015.

BERTOLLI FILHO, Cláudio.

História da saúde pública no Brasil. São Paulo: Ática. 2011.

BOLETIM DA LBA.

Boletim da LBA, n.111. jul.-set. 1963.

BOLETIM DA LBA.

Boletim da LBA, n.108. out.-dez. 1961.

BOLETIM DA LBA.

Boletim da LBA, n.107. jul.-set. 1961.

BOLETIM DA LBA.

Boletim da LBA, n.102. dez. 1959.

BOLETIM DA LBA.

Boletim da LBA, n.87. jul.-set. 1957.

BOLETIM DA LBA.

Boletim da LBA, n.83. jul.-set. 1956.

BOLETIM DA LBA.

Boletim da LBA, n.81. jan.-mar. 1956.

BOLETIM DA LBA.

Boletim da LBA, n.82. abr.-jun. 1952.

BOLETIM DA LBA.

Boletim da LBA, n.74. jan. 1952.

BOLETIM DA LBA.

Boletim da LBA, n.72. nov. 1951.

BOLETIM DA LBA.

Boletim da LBA, n.71. out. 1951.
BOLETIM DA LBA.

Boletim da LBA, n.70. set. 1951.

BOLETIM DA LBA.

Boletim da LBA, jun. 1951.

BOLETIM DA LBA.

Boletim da LBA, n.66. abr.-maio 1951.

BOLETIM DA LBA.

Boletim da LBA, n.65. mar. 1951.

BOLETIM DA LBA.

Boletim da LBA, n.63. jan. 1951.

BOLETIM DA LBA.

Boletim da LBA, n.27. set. 1947.

BOLETIM DA LBA.

Boletim da LBA, n.26. ago. 1947.

BOLETIM DA LBA.

Boletim da LBA, n.25. jun.-jul. 1947.

BOLETIM DA LBA.

Boletim da LBA, n.18. 1 mar. 1946.

BOURDIEU, Pierre.

O poder simbólico. Tradução Fernando Thomaz. Rio de Janeiro: Bertrand. 2001.

CESBRON, Paul.

Naître à la vie, en douleur. Spirale, n.45, p.79-98. Disponível em: <https://www.cairn.info/revuespirale-2008-1-page-79.htm>. Acesso em: 25 jun. 2017. 2008.

CÔRTES, Iáris Ramalho.

A trilha legislativa da mulher. In: Pinsky, Carla Bassanezi; Pedro, Joana Maria. A nova história das mulheres no Brasil. São Paulo: Contexto. p.260-285. 2012.

COSTA, Jurandir Freire.

Ordem médica e norma familiar. Rio de Janeiro:

Graal. 1999.

DEL PRIORE, Mary.

A mulher na história do Brasil. São Paulo:

Contexto. 1994. 
DINIZ, Carmen Simone Grilo.

Assistência ao parto e relações de gênero: elementos para uma releitura médico-social. Dissertação (Mestrado) - Faculdade de Medicina de São Paulo, São Paulo. 1996.

ESCOREL, Sarah; TEIXEIRA, Luiz Antonio. História das políticas de saúde no Brasil de 1822 a 1963: do Império ao desenvolvimento populista. In: Giovanella, Lígia; Escorel, Sarah et al. (Org.). Políticas e sistemas de saúde no Brasil. Rio de Janeiro: Editora Fiocruz. 2008.

FERRAZ, Francisco César Alves.

A guerra que não acabou: a reintegração social dos veteranos da Força Expedicionária Brasileira, 1945-2000. Londrina: Eduel. 2012.

FOUCAULT, Michel.

O nascimento da clínica. Rio de Janeiro: Forense Universitária. 2004.

FOUCAULT, Michel.

Microfísica do poder. Tradução e organização Roberto Machado. Rio de Janeiro: Graal. 1979.

FREDDI, Wanda Escobar da Silva.

Preparo da gestante para o parto. Revista Brasileira de Enfermagem, v.26, n.3, p.108120. Disponível em: <http://www.scielo. br/scielo.php?script=sci_arttext\&pid $=$ S0034-71671973000200108 $>$. Acesso em: 15 jun. 2017. 1973.

FREIRE, Maria Martha Luna.

Mulheres, mães e médicos: discurso maternalista no Brasil. Rio de Janeiro: FGV Editora. 2009.

GOMES, Angela de Castro.

População e sociedade. In: Gomes, Ângela de Castro (Coord.). Olhando para dentro, 1930-1964. Madrid: Fundación Mapfre; Rio de Janeiro: Objetiva. p.41-89. (Coleção História do Brasil Nação, 1808-2010, v.4). 2013.

HOCHMAN, Gilberto. KOBAYASHI, Elizabete. $\mathrm{O}$ "cc" e a patologização do natural: higiene, publicidade e modernização no Brasil do pósSegunda Guerra Mundial. Anais do Museu Paulista, v.23, n.1, p.67-89. 2015.

LUCA, Tania Regina de.

Mulher em revista. In: Pinsky, Carla; Pedro, Joana Maria (Org.). Nova história das mulheres no Brasil. São Paulo: Contexto. p.447-468. 2012.

MARTINS, Ana Paula Vosne.

"Vamos criar seu filho": os médicos puericultores e a pedagogia materna no século XX. História, Ciências, Saúde-Manguinhos, v.5, n.1, p.135-154. 2008.

MARTINS, Ana Paula Vosne.

A medicina da mulher: visões do feminino na constituição da obstetrícia e da ginecologia no século XIX. Tese (Doutorado) - Universidade Estadual de Campinas, Campinas. 2000.

MOTT, Maria Lúcia.

Maternalismo, políticas públicas e benemerência no Brasil, 1930-1945. Cadernos Pagu, n.16, p.199234. Disponível em: <http://dx.doi.org/10.1590/ S0104-83332001000100010>. Acesso em: 8 abr. 2017. 2001.

MOTT, Maria Lúcia.

A parteira ignorante: um erro de diagnóstico médico? Revista Estudos Feministas, v.7, n.1-2, p.25-36. 1999.

PINSKY, Carla Bassanezi.

Mulheres dos Anos Dourados. In: Del Priore, Mary. História das mulheres no Brasil. São Paulo: Contexto. p.607-639. 2010.

SCHWARCZ, Lilia Moritz.

O espetáculo das raças: cientistas, instituições e questão racial no Brasil, 1870-1930. São Paulo: Companhia das Letras. 1993.

VIEIRA, Elisabeth.

A medicalização do corpo feminino. Rio de Janeiro: Editora Fiocruz. 2002. 